\title{
Crescimento e acúmulo de nutrientes em mudas de aceroleiras em função da aplicação de diferentes doses de nitrogênio e potássio
}

Karine Simões Ferreira ${ }^{1}$, José Carlos Moraes Rufini ${ }^{1}$, Miriã Cristina Pereira Fagundes ${ }^{1}$, Silvino Guimarães Moreira $^{2}$, Eric Victor de Oliveira Ferreira ${ }^{3}$, Mariana Alves Pinto Barbosa ${ }^{1}$

${ }^{1}$ Universidade Federal de São João Del Rei - UFSJ. ${ }^{2}$ Universidade Federal de Lavras - UFLA. ${ }^{3}$ Universidade Federal Rural da Amazônia - UFRA. E-mail: miria.agro@yahoo.com.br

\section{Resumo}

Com o objetivo de estudar o efeito de doses de nitrogênio $(\mathrm{N})$ e potássio $(\mathrm{K})$ no crescimento e acúmulo de nutrientes na parte aérea de mudas de aceroleira (Malpighia emarginata D.C), instalou-se um experimento em casa de vegetação na Universidade Federal de São João Del Rei-UFSJ em Sete Lagoas, MG, utilizando-se mudas oriundas do processo de estaquia. Utilizou-se o esquema fatorial $4 \times 4$, em delineamento de blocos casualizados, com três repetições e três plantas por parcela. Os fatores consistiram de quatro doses de $\mathrm{N}(0$, 200,400 e $\left.600 \mathrm{mg} \mathrm{dm}^{-3}\right)$ e quatro doses de $\mathrm{K}\left(0,100,200\right.$ e $\left.300 \mathrm{mg} \mathrm{dm}^{-3}\right)$. Aos 110 dias após o transplantio, as mudas foram avaliadas quanto ao comprimento de parte aérea e raiz, diâmetro do caule, número de folhas e Índice de Qualidade de Dickson, posteriormente foram colhidas, secas em estufa a $65{ }^{\circ} \mathrm{C}$ para a obtenção da matéria seca da parte aérea, raiz e total, sendo trituradas para a determinação da concentração de nutrientes. Foram determinadas as quantidades acumuladas de $\mathrm{N}, \mathrm{P}, \mathrm{K}, \mathrm{Ca}, \mathrm{Mg}, \mathrm{S}, \mathrm{B}, \mathrm{Cu}$, $\mathrm{Zn}$, Fe e $\mathrm{Mn}$ na matéria seca da parte aérea. As doses isoladas de $\mathrm{N}$ e $\mathrm{K}$ influenciaram as variáveis de crescimento e aumentaram as quantidades acumuladas de $\mathrm{P}, \mathrm{K}$ e $\mathrm{Zn}$, sendo as quantidades acumuladas dos demais nutrientes afetadas apenas pelo $\mathrm{N}$. $\mathrm{O}$ acúmulo dos nutrientes nas mudas seguiu a ordem decrescente $\mathrm{N}>\mathrm{Ca}>\mathrm{Mg}>\mathrm{P}>\mathrm{S}>\mathrm{K}>\mathrm{Mn}>\mathrm{B}>\mathrm{Zn}>\mathrm{Fe}$.

Palavras- chave: Malpighia emarginata; nutrientes; qualidade de muda.

Growth and accumulation of nutrients by barbados cherry seedlings in the function of the application of different doses of nitrogen and potassium

\begin{abstract}
In order to study the effect of nitrogen $(\mathrm{N})$ and potassium $(\mathrm{K})$ rates on the growth and nutrient accumulation of shoot shoots (Malpighia emarginata DC), an experiment was carried out under greenhouse conditions at Federal University of São João Del Rei-UFSJ in Sete Lagoas, MG, using seedlings from the cutting process. A $4 \times 4$ factorial scheme was used in a randomized complete block design with three replications and three plants per plot. The factors consisted of four doses of $N(0,200,400$ and $600 \mathrm{mg}$ $\left.\mathrm{dm}^{-3}\right)$ and four doses of $\mathrm{K}\left(0,100,200\right.$ and $\left.300 \mathrm{mg} \mathrm{dm}^{-3}\right)$. At 110 days after transplanting, the seedlings were evaluated for root length, root diameter, stem number, leaf number and Dickson Quality Index, and were then harvested, oven dried at $65^{\circ} \mathrm{C}$ to obtain the material dry matter of the aerial part, root and total, being crushed for the determination of the concentration of nutrients. The accumulated amounts of N, P, K, $\mathrm{Ca}, \mathrm{Mg}, \mathrm{S}, \mathrm{B}, \mathrm{Cu}, \mathrm{Zn}, \mathrm{Fe}$ and $\mathrm{Mn}$ in the shoot dry matter were determined. The isolated doses of $\mathrm{N}$ and $\mathrm{K}$ influenced the growth variables and increased the accumulated amounts of $P, K$ and $Z n$, the accumulated amounts of the other nutrients being affected only by $\mathrm{N}$. The accumulation of nutrients in the seedlings followed the decreasing order $\mathrm{N}>\mathrm{Ca}>\mathrm{Mg}>\mathrm{P}>\mathrm{S}>\mathrm{K}>\mathrm{Mn}>\mathrm{B}>\mathrm{Zn}>\mathrm{Fe}$.

Keywords: Malpighia emarginata; nutrients; quality of seedling.
\end{abstract}




\section{Introdução}

A acerola é uma fruta que contém altos teores de vitamina C (ASSIS et al., 2001), sendo este seu principal atrativo em termos nutricionais, elevando sua demanda e, em consequência, o plantio comercial. Atualmente uma das maiores limitações para a ampliação das áreas de cultivo com essa frutífera é a obtenção de mudas de qualidade, principalmente devido a falta de estudos envolvendo a absorção de nutrientes e os requerimentos nutricionais dessa espécie.

Na produção de mudas a adubação é uma prática extremamente importante, para 0 fornecimento de nutrientes de forma adequada e equilibrada, principalmente o nitrogênio (N) e o potássio (K) por serem nutrientes exigidos em maiores quantidades para $\mathrm{o}$ crescimento $\mathrm{e}$ desenvolvimento da planta.

O nitrogênio desempenha um papel importante na composição de várias biomoléculas, está presente no trifosfato de adenosina (ATP), clorofila, proteínas e muitas enzimas (HARPER, 1994), além de ser o precursor da auxina (Ácido Indolacético) e do etileno importantes hormônios vegetais (FAQUIN, 1994). $\mathrm{O} N$ absorvido pela planta é incorporado na forma de aminoácido, e a medida que há um acúmulo desse nutriente, ocorre o crescimento foliar, resultando em uma maior superfície fotossintética (DECHEN; NACHTIGALL, 2007).

O potássio apesar de não fazer parte de nenhuma estrutura ou biomoléculas, desempenha um importante papel em muitos processos fisiológicos, incluindo a fotossíntese, o equilíbrio entre cátions e ânions, turgor do tecido vegetal, processos de transporte de elétrons, regulação osmótica, a ativação de muitas enzimas, além de participar na síntese proteica (OOSTERHUIS et al., 2014).

Além disso, tem-se uma interação positiva entre $\mathrm{N}$ e $\mathrm{K}$, isso se deve ao fato do $\mathrm{K}$ participar ativamente do metabolismo do N. Alguns autores defendem que esse elemento participa na fase inicial do metabolismo como incorporação do nitrogênio mineral e especialmente na ativação e síntese redutase do nitrato (ARMENGAUD et al., 2009), enquanto outros defendem que o $\mathrm{K}$ participa na fase do metabolismo final com $o$ acúmulo de compostos solúveis de $\mathrm{N}$ (aminoácidos, amido e nitrato) (MENGEL; HELAL, 1968).

A adubação nitrogenada e potássica para a produção de mudas isoladamente ou em conjunto tem sido estudada para algumas espécies frutíferas como camu-camuzeiro (ABANTO-RODRÍGUEZ et al., 2014), goiabeira (DIAS et al., 2012), jaqueira (SILVA et al., 2014), mamoeiro (MENDONÇA et al., 2009), maracujazeiro e (ALMEIDA et al., 2014; MIYAKE et al., 2017).

Entretanto, para a produção de mudas de aceroleira, se dispõe, ainda, de poucas informações técnicas sobre adubação básica, havendo necessidade de estudos. Com isso, objetivou-se avaliar o crescimento e acúmulo de nutrientes em mudas de aceroleiras em função da aplicação de diferentes doses de nitrogênio e potássio.

\section{Material e Métodos}

O experimento foi conduzido entre setembro de 2013 e janeiro de 2014, em casa de vegetação climatizada com temperatura ajustada para $25^{\circ} \mathrm{C}$, no Campus da Universidade Federal de São João Del Rei (UFSJ), em Sete Lagoas - MG. Foram utilizadas mudas propagadas por estaquia de planta matriz de aceroleira de um pomar comercial, localizado em Jequitibá-MG.

Utilizou-se o esquema fatorial $4 \times 4$, com delineamento em blocos casulizados, com três repetições totalizando 16 tratamentos, em que cada parcela foi constituída de três plantas. Os fatores consistiram de quatro doses de $\mathrm{N}(0,200$, 400 e $\left.600 \mathrm{mg} \mathrm{dm}^{-3}\right)$ e quatro doses de $\mathrm{K}(0,100$, 200, $300 \mathrm{mg} \mathrm{dm}^{-3}$ ), aplicados na forma de ureia e cloreto de potássio, respectivamente. Os nutrientes $\mathrm{N}$ e $\mathrm{K}$ foram aplicados de forma parcelada em quatro doses (divididas em partes iguais por aplicação), sendo a primeira no transplantio e as demais aos 30, 45 e 60 dias após o transplantio. Para complementar a adubação, foram aplicados os seguintes nutrientes $\left(\mathrm{mg} \mathrm{dm}^{-3}\right.$ de substrato): $P$ (450), antes do transplantio misturados ao substrato em dose única, conforme Corrêa et al. (2002); Zn (5,0); B $(0,5)$; Cu $(1,5)$ e S $(40,0)$, adaptados de Malavolta (1980), diluídos em solução.

O transplantio das mudas foi realizado após 60 dias do enraizamento das estacas. Utilizaram se vasos de $2 \mathrm{dm}^{3}$, preenchidos com substrato agrícola comercial (HS Florestal/Holambra Substratos), cuja análise química encontra-se na Tabela 1. As mudas utilizadas continham acima de 3 raízes e 2 brotações.

Aos 110 dias após o transplantio, foi feita a avaliação em relação ao crescimento e aos teores de nutrientes das mudas. Para determinação do 
crescimento foram avaliados: comprimento da parte aérea e sistema radicular, diâmetro do caule, número de folhas, matéria seca da parte aérea e das raízes.

Tabela 1. Resultado da análise química do substrato HS Florestal/Holambra Substratos.

\begin{tabular}{|c|c|c|c|c|c|c|c|c|c|}
\hline $\mathrm{pH}$ & $\mathrm{P}$ & $\mathrm{K}$ & $\mathrm{Ca}$ & $\mathrm{Mg}$ & Al & $\mathrm{H}+\mathrm{Al}$ & $\mathrm{t}$ & $\mathrm{T}$ & SB \\
\hline $\mathrm{H}_{2} \mathrm{O}$ & \multicolumn{2}{|c|}{$---m g d m^{-3}----$} & \multicolumn{7}{|c|}{ 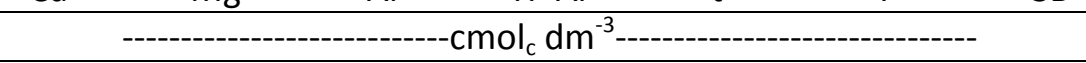 } \\
\hline 5,02 & 223,55 & 47,56 & 7,47 & 2,73 & 0,43 & 14,20 & 10,75 & 24,52 & 10,32 \\
\hline MO & $\mathrm{M}$ & $\mathrm{V}$ & $\mathrm{S}$ & B & $\mathrm{Fe}$ & $\mathrm{Zn}$ & $\mathrm{Cu}$ & \multicolumn{2}{|c|}{$\mathrm{Mn}$} \\
\hline \multicolumn{4}{|c|}{--------------\%------------ } & \multicolumn{6}{|c|}{------------------------------'mg dm } \\
\hline 4,70 & 4 & 42 & - & 12,70 & 27,72 & 5,65 & 1,74 & & \\
\hline
\end{tabular}

$\mathrm{P}, \mathrm{K}, \mathrm{Cu}, \mathrm{Fe}, \mathrm{Mn}$ e $\mathrm{Zn}$ - Extrator Mehlich; Ca, Mg e Al - Extrator $\mathrm{KCl} ; \mathrm{H}+\mathrm{Al}$ - Extrator Acetato de Cálcio; MO - Matéria orgânica $=\mathrm{C}$. org $\times 1,724 ; \mathrm{SB}$ - Soma de bases; $\mathrm{t}$ - Capacidade de troca de cátions efetiva; $\mathrm{T}$ - Capacidade de troca de cátions em pH 7,0; M - Saturação de alúminio; $V$ - Saturação por bases.

A determinação do comprimento da parte aérea da muda foi realizada medindo-se a distância entre o colo e o ápice utilizando-se uma régua graduada em centímetros. 0 comprimento da raiz foi obtido através da mensuração da distância entre o colo e a extremidade da raiz. Para o diâmetro foi utilizado um paquímetro digital, o número de folhas foram contabilizados manualmente. A matéria seca da parte aérea e do sistema radicular foi obtida após secagem em estufa com circulação forçada de ar e temperatura de $65{ }^{\circ} \mathrm{C}$, até matéria constante e posterior pesagem em balança analítica. Em seguida, a matéria seca da parte aérea foi passada em moinho do tipo Willey (peneira de 20 mesh) e armazenadas em potes de polietileno hermeticamente fechados. Após a obtenção das amostras, foram determinados os teores de macro e micronutrientes $(\mathrm{N}, \mathrm{P}, \mathrm{K}, \mathrm{Ca}, \mathrm{Mg}, \mathrm{S}, \mathrm{B}, \mathrm{Cu}$, $\mathrm{Fe}, \mathrm{Mn}$ e $\mathrm{Zn}$ ), conforme metodologia descrita por Malavolta et al. (1997).

As quantidades acumuladas de nutrientes foram estimadas baseando-se na concentração dos mesmos e nas quantidades correspondentes de matérias secas produzidas por parcela. Como cada parcela era constituída de três plantas, o resultado obtido foi dividido por esse número de plantas. Para efeito de acúmulo na parte aérea, os teores macronutrientes foram transformados em miligramas planta $^{-1}$ (mg planta ${ }^{-1}$ ) e dos micronutrientes em microgramas planta $^{-1}$ ( $\mu \mathrm{g}$ planta $\left.^{-1}\right)$.

A partir das características de crescimento calculou-se o índice de qualidade de Dickson (IQD) para mudas, por meio da fórmula (DICKSON et al., 1960):

em que
MST = Matéria seca total;

$\mathrm{H}=$ Altura;

$\mathrm{D}=$ Diâmetro;

MSPA = Matéria seca da parte aérea (folhas + caule);

MSR = Matéria seca das raízes.

Os dados obtidos foram submetidos à análise de resíduos; para verificar as pressuposições da análise de variância e posteriormente a análise de variância $(p \leq 0,05)$ e, quando constatada significância, foi feito o ajuste aos modelos de regressão. Os cálculos foram realizados com uso do programa SISVAR (FERREIRA, 2011). Também foi calculado o coeficiente de correlação de Pearson para avaliar a correlação entre as variáveis de crescimento.

\section{Resultados e Discussão Crescimento}

A análise dos dados indicou influência das doses de nitrogênio para todas as variáveis analisadas e das doses de potássio para o comprimento da parte aérea (CPA), número de folhas (NF) e matéria seca total (MST). A interação entre as doses de $\mathrm{N}$ e $\mathrm{K}$ exerceu efeito significativo somente sobre matéria seca da parte aérea (MSPA) em mudas de aceroleira.

O comprimento da parte aérea e o número de folhas foram influenciados por ambos os nutrientes isoladamente (Figura 1).

O máximo comprimento da parte aérea das mudas de aceroleiras em relação a adubação foi estimado com a dose de $516 \mathrm{mg} \mathrm{dm}^{-3}$ de $\mathrm{N}$, alcançando $55,24 \mathrm{~cm}$, o que significa um incremento de $39,69 \mathrm{~cm}$ em relação a ausência desse nutriente (Figura 1A). Tais resultados foram semelhantes aos resultados encontrados por Mendonça et al. (2010), trabalhando com 
porta-enxertos de cajueiro-gigante, onde observou uma resposta quadrática, em relação a altura, quando as plantas foram submetidas a diferentes doses desse nutriente. Entretanto os resultados diferiram do trabalho de Silva et al. (2014), que estudando diferentes doses de nitrogênio no crescimento inicial de mudas de jaqueira, constatou comportamento linear decrescente com o aumento das doses.

O nitrogênio possui função estrutural na planta, e é essencial para o crescimento vegetativo, sendo relacionado com principais processos vitais do ciclo vegetal, tais como, a fotossíntese, respiração, desenvolvimento e atividade das raízes, absorção iônica de outros nutrientes, crescimento e diferenciação celular. Também é parte integrante de todos os aminoácidos, os quais compõem as proteínas (MARSCHNER, 1995). Portanto, as principais mudanças morfo-fisioloógicas sofridas pelas plantas é devido ao nitrogênio (LEAL et al., 2007)

Figura 1. Comprimento de parte aérea $(A$ e $B$ ) e número de folhas $(C$ e $D)$ de mudas de aceroleiras em função da adubação nitrogenada e potássica isoladamente.
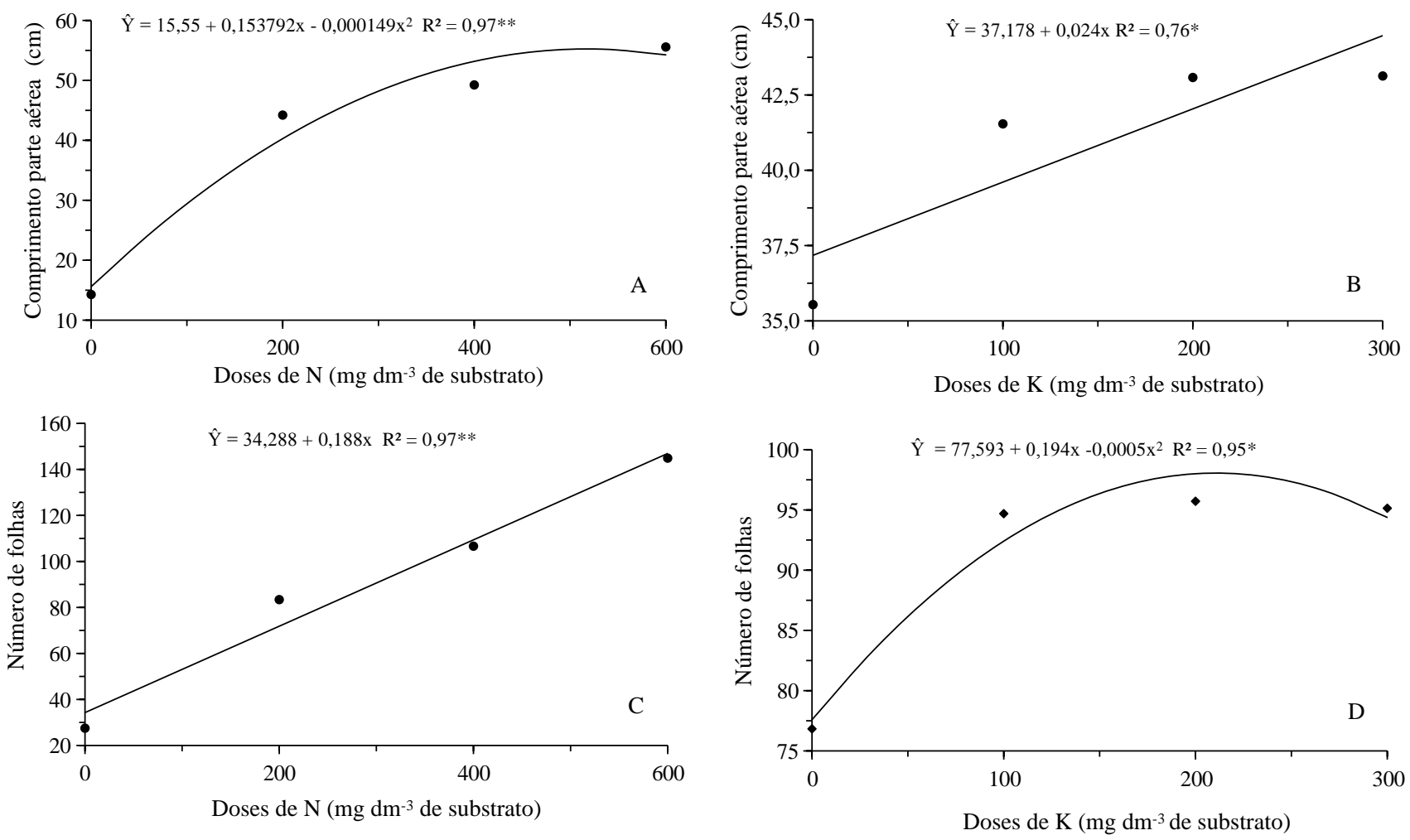

Em relação a adubação potássica o maior comprimento da parte aérea foi na dose de 300 $\mathrm{mg} \mathrm{dm}^{-3}(44,38 \mathrm{~cm})$, o que promoveu um aumento de $7,2 \mathrm{~cm}$ na altura em relação a dose zero, com uma incremento de 19,37\% (Figura 1B). Segundo Lebaudy et al. (2007) o K é um nutriente envolvido na translocação do floema de assimilados, podendo assim, possibilitar um maior crescimento e desenvolvimento da planta.

$\mathrm{O}$ número de folhas apresentou comportamento linear para as doses de $\mathrm{N}$ e quadrático para as doses de $\mathrm{K}$ (Figura $1 \mathrm{C}$ e $1 \mathrm{D}$ ). Para as doses de $\mathrm{N}$ o máximo numero de folhas (145) foi obtido na concentração de $600 \mathrm{mg} \mathrm{dm}^{-3}$, resultando em um incremento de 117 folhas. Com o ajuste da equação da quadrática, a dose

de $\mathrm{K}$ que proporcionou o maior número de folhas foi $194 \mathrm{mg} \mathrm{dm}-3$, proporcionando uma média de 94,4 folhas.

Resultados semelhantes foram relatados por Miyake et al. (2017) trabalhando com doses de N e diferentes substratos para a produção de mudas de maracujazeiro, onde constatou o aumento do número de folhas em maracujazeiro com na concentração de $600 \mathrm{mg} \mathrm{dm}^{-3}$ de $\mathrm{N}$ com o uso do substrato Bioplant e um maior número de folhas utilizando o substrato fibra de coco, tal fato é justificado pelo autor devido à presença de uma grande quantidade de potássio na fibra de coco, evidenciando a necessidade da adubação potássica na produção de mudas, uma vez que o potássio que é de extrema importância para o 
metabolismo e acúmulo de matéria seca (MALAVOLTA et al., 2006). Apesar de isoladamente o número de folhas não ser uma boa característica para avaliar a qualidade de mudas, quando relacionada com a altura e a matéria seca é uma excelente característica no padrão da análise de qualidade de mudas, ou seja, quanto maior, melhor nutrida está a planta.

Figura 2. Comprimento radicular (A ), diâmetro do caule (B), matéria seca radicular (C) e índice de qualidade de Dickson (D) de mudas de aceroleiras em função da adubação nitrogenada.
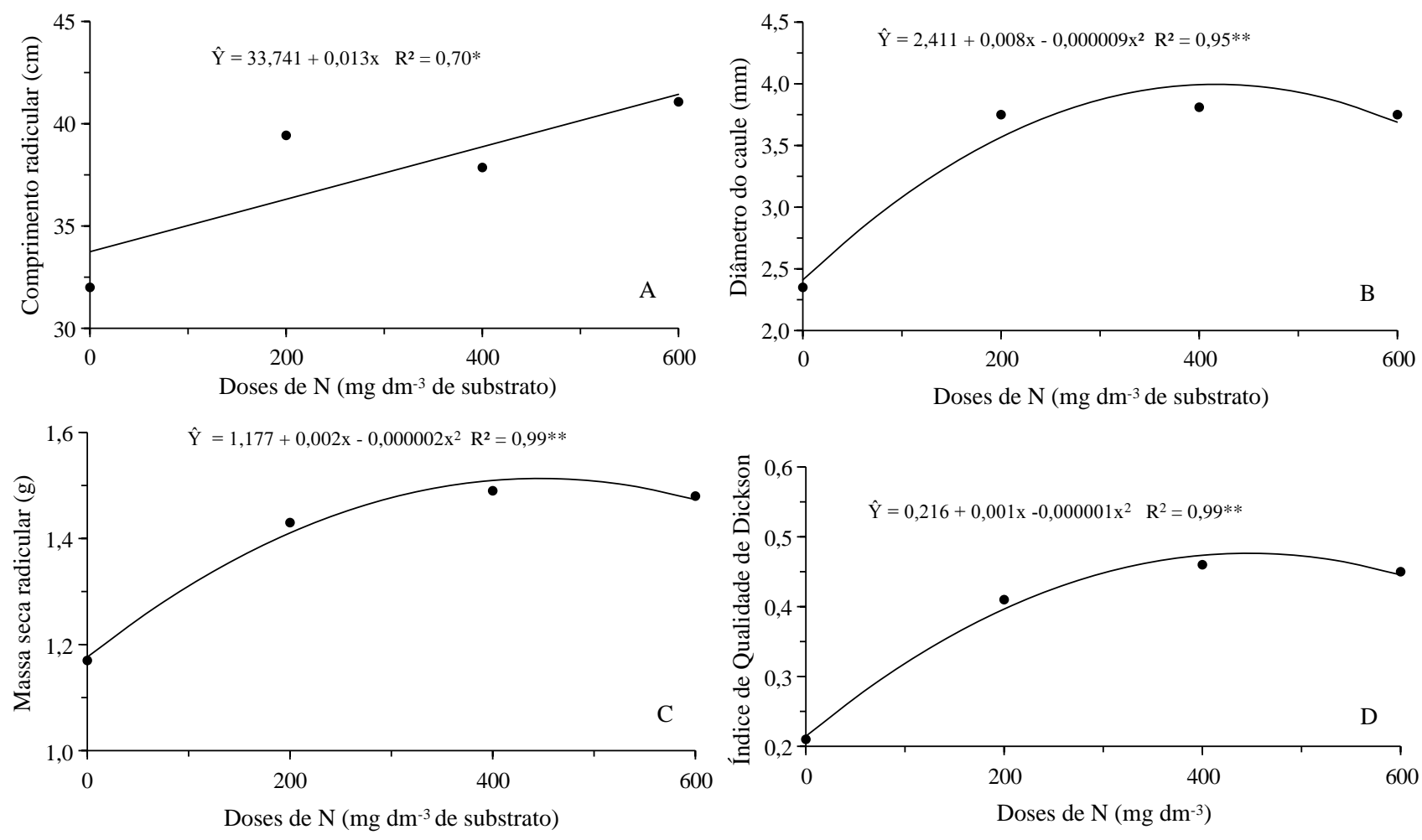

O maior comprimento radicular $(41,54 \mathrm{~cm})$ foi verificado na dose de $600 \mathrm{mg} \mathrm{dm}^{-3}$ o que representou um ganho de $23 \%$ em relação a testemunha (Figura 2A). Isso pode ser explicado pela adequada disponibilidade de nutrientes no substrato que otimizou o crescimento radicular. Segundo Marschner (1995), em solos com maior disponibilidade de $\mathrm{N}$ ocorre aumento do crescimento radicular.

$\mathrm{Na}$ Figura 2B observa-se com o ajuste da equação quadrática o maior diâmetro do colo para as mudas de aceroleiras com a dose estimada de $444,0 \mathrm{mg} \mathrm{dm}^{-3,}$ de $\mathrm{N}$ promovendo um acréscimo de $1,72 \mathrm{~mm}$ e um ganho de $74 \%$ quando comparado a testemunha, sendo que acima dessa dose, o diâmetro do caule apresentou tendência à estabilização e queda, típico de curvas de resposta à aplicação de nutrientes. Comportamento semelhante foram observados por Dias et al. (2012), estudando o
Observou-se comportamento linear para o comprimento radicular (Figura $2 \mathrm{~A}$ ) e quadrático para o diâmetro do colo (Figura 2B), matéria seca de raiz (Figura $2 \mathrm{C}$ ) e índice de qualidade de Dickson (Figura 2D), quando submetidos a diferentes doses de $\mathrm{N}$.

crescimento de mudas de goiabeiras sob adubação potássica e nitrogenada, onde não se constatou influência do K sob o diâmetro do caule das mudas e o $\mathrm{N}$ teve comportamento quadrático com ganho de $60 \%$ em relação a testemunha na dose de $667 \mathrm{mg} \mathrm{dm}^{-3}$. Já Neves et al. (2007), não observou interferência da adubação nitrogenada sobre o diâmetro do caule em mudas de umbuzeiro.

O diâmetro do caule é o parâmetro mais utilizado para indicar a capacidade de sobrevivência da muda no campo, mostrando a necessidade de se estabelecer doses de fertilizantes para serem aplicadas na produção de mudas (DANIEL et al., 1997).

A dose de $500 \mathrm{mg} \mathrm{dm}^{-3}$ de $\mathrm{N}$ proporcionou acréscimo no acúmulo de matéria seca radicular de 0,503 g, alcançando um valor máximo de 1,68 $\mathrm{g}$, decrescendo a partir dessa dose (Figura 2C). Possivelmente, doses acima da mencionada 
anteriormente podem ter limitado $\mathrm{o}$ desenvolvimento e manutenção do crescimento radicular pelo excesso de nitrogênio presente no substrato ou através da limitação física do tamanho do recipiente. Segundo Durieux et al. (1994), quando os nutrientes no substrato excedem um nível ótimo, o crescimento radicular fica limitado pela falta de carboidratos e eventualmente cessa.

De acordo com Hermann (1964), o peso de matéria seca das raízes tem sido reconhecido como um dos melhores e mais importantes parâmetros para a sobrevivência e estabelecimento das mudas no campo.

A dose de $\mathrm{N}$ que promoveu o máximo índice de qualidade de Dickson (IQD) $(0,47)$ foi a de 500 $\mathrm{mg} \mathrm{dm^{-3 }}$, com um ganho de $113 \%$ em relação à testemunha. Esses resultados estão de acordo com os resultados encontrados por Dickson et al. (1960), onde os autores classificaram como boas, mudas de abeto branco com índice variando de 0,459-0,196, com média de 0,303. Segundo
Caldeira et al. ( 2012) quanto maior for o IQD, melhor será a qualidade da muda produzida. Respostas positivas para as doses de $\mathrm{N}$ também foram relatadas por Dias et al. (2012) com efeito quadrático em mudas de goiabeira. Este índice é normalmente utilizado na produção de mudas de espécies florestais, mas as mesmas características que concebem o IQD são importantes para a produção de mudas frutíferas.

A produção de matéria seca da parte aérea da aceroleira aumentou com o suprimento combinado de nitrogênio e potássio (Figura 3). De acordo com a estimativa da equação quadrática, verificou-se que a dose de $596,2 \mathrm{mg} \mathrm{dm}^{-3}$ de nitrogênio foi responsável pela máxima produção de matéria seca da parte aérea $(8,05 \mathrm{~g})$, associada à dose de $100 \mathrm{mg} \mathrm{dm}^{-3}$ de potássio. Estas doses promoveram incremento produtivo da parte aérea, resultando em um aumento de $4,62 \mathrm{~g}$.

Figura 3. Matéria seca da parte aérea de mudas de aceroleiras em função da adubação nitrogenada.

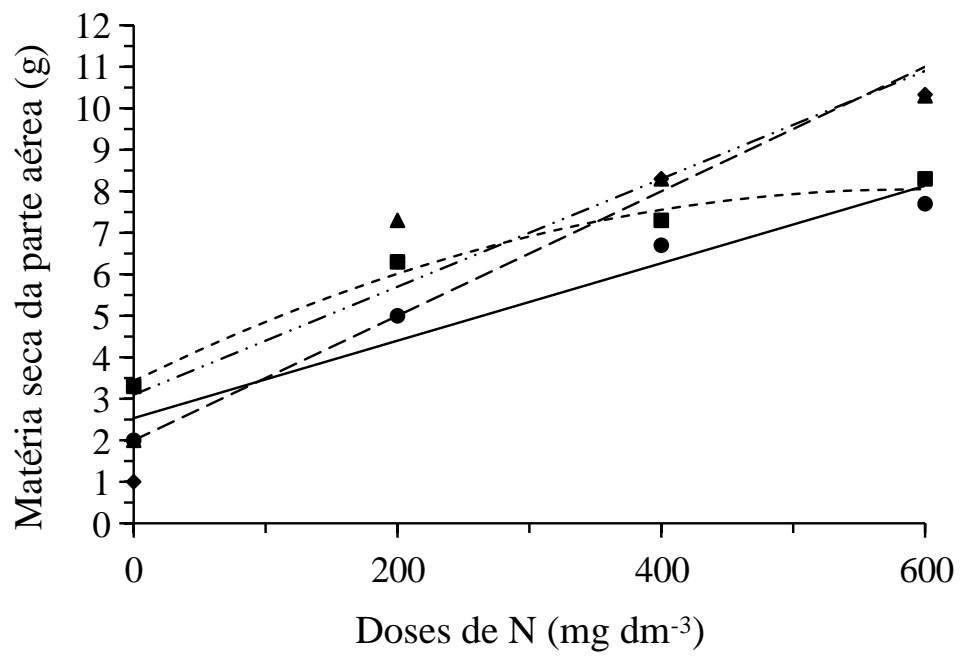

- $\mathrm{K}(0) \hat{\mathrm{Y}}=2,53333+0,00933 \mathrm{x} \mathrm{R}^{2}=0,95 * *$

- $\mathrm{K}(100) \hat{\mathrm{Y}}=3,4333+0,0155 \mathrm{x}-0,000013 \mathrm{x}^{2} \mathrm{R}^{2}=0,98^{* *}$

- $\mathrm{K}(200) \hat{\mathrm{Y}}=2,0+0,015 \times \mathrm{R}^{2}=0,93^{* * *}$

- $\mathrm{K}(300) \hat{\mathrm{Y}}=3,10+0,013 \mathrm{x} \mathrm{R}^{2}=0,89 * *$

A matéria seca total apresentou comportamento quadrático em relação a suplementação com diferentes doses de $\mathrm{N}$ (Figura 4A) e linear para $K$ (Figura 4B). Verificou-se a máxima matéria seca total 10, 27 g e 7,83 g com a dose estimada de $616,15 \mathrm{mg} \mathrm{dm}-3$ de $\mathrm{N}$ e $300 \mathrm{mg}$ $\mathrm{dm}^{-3}$ de $\mathrm{K}$, respectivamente. Isso representou um aumento de 7,59 g e 1,75 g quando comparado com a ausência de $\mathrm{N}$ e K. Esses resultados corroboraram com os encontrados por Miyake et 
al. (2017) e Dias et al. (2012), onde observaram comportamento quadrático da matéria seca total com suplementação de $\mathrm{N}$ em mudas de maracujazeiro e goiabeira. Em relação à suplementação potássica os resultados do presente trabalho diferiram dos encontrados por
Paula et al. (2009), para produção de porta-enxertos de tamarindo, que apresentou uma resposta quadrática em relação as diferentes doses de potássio.

Figura 4. Matéria seca total (A e B) de mudas de aceroleiras em função da adubação nitrogenada e potássica isoladamente.

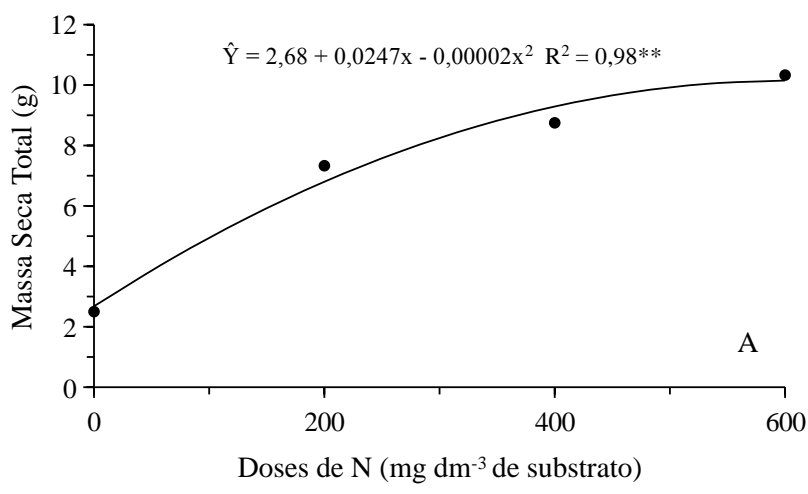

A produção de matéria seca tem sido apontada como um dos melhores parâmetros para verificar a qualidade de mudas, apresentando, contudo, o inconveniente da não viabilidade para ser determinada em muitos viveiros, principalmente, por envolver a destruição completa da muda e a utilização de estufas (AZEVEDO, 2003).

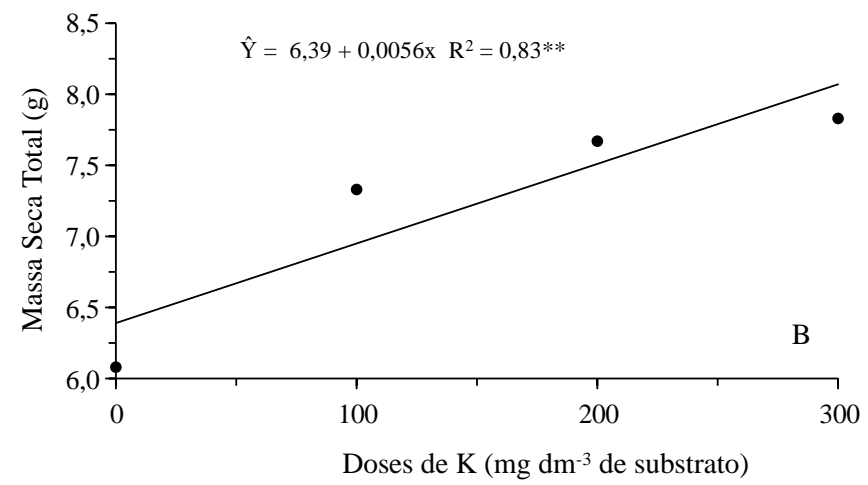

Buscando-se uma alternativa ao entrave do uso da matéria seca total como parâmetro para verificar a qualidade de mudas observou-se correlação positiva entre todos os parâmetros não destrutivos e a matéria seca total (Tabela 2).

Tabela 2. Correlação de Person entre as variáveis Número de folhas (NF), Comprimento da parte aérea (CPA), Diâmetro do caule (DC) e Matéria seca total (MST) para mudas de aceroleiras.

\begin{tabular}{llll}
\hline Caraterísticas & NF & CPA & DC \\
\hline MST & $0,91^{* *}$ & $0,93^{* *}$ & $0,84^{* *}$ \\
NF & & $0,89^{* *}$ & $0,73^{* *}$ \\
CPA & & & $0,87^{* *}$ \\
\hline
\end{tabular}

Observa-se correlação alta e positiva entre as variáveis NF, CPA, DC e MST, mostrando que pode-se utilizar estas variáveis para a determinação da qualidade de mudas de aceroleira, visto que todos os coeficientes foram significativos a $1 \%$ de probabilidade de erro. A correlação, acima de 0,7 , entre as variáveis dependentes indica que a observação de uma variável possibilitaria inferir sobre as outras. Assim sendo, a variável comprimento parte aérea é a que apresenta o maior valor de correlação 0,93, mostrando-se como bom indicador para a qualidade de mudas.

De acordo com Gomes et al. (2002) a altura é amplamente utilizada para avaliar a qualidade das mudas, devido ao fato de ser um método de fácil execução, não destrutivo e disponível a todos os produtores. Segundo o mesmo autor citado acima, para a determinação da qualidade das mudas, os parâmetros utilizados devem se basear em aspectos morfológicos, os quais dependem também da genética e da procedência do material propagado, das condições ambientais e das técnicas de produção em nível de viveiro.

\section{Acúmulo de nutrientes}

$O$ efeito do nitrogênio foi significativo para o acúmulo de $\mathrm{N}, \mathrm{P}, \mathrm{K}, \mathrm{Ca}, \mathrm{Mg}, \mathrm{S}, \mathrm{Zn}, \mathrm{Fe}, \mathrm{Mn}$ e $\mathrm{B}$, enquanto o efeito do potássio foi restrito ao acúmulo de $P, K$ e $Z n$, contudo não foram suficientes para chegar na inflexão da curva, indicando que os maiores acúmulos destes nutrientes podem não ter sido alcançados com as 
doses de $\mathrm{N}$ e $\mathrm{K}$ utilizadas no presente estudo. $\mathrm{A}$ interação entre os fatores, doses de nitrogênio e doses de potássio, não foi significativa para nenhuma das variáveis estudadas, o $\mathrm{Cu}$ não foi influenciado por nenhum dos tratamentos.

$\mathrm{O}$ acúmulo de $\mathrm{N}$ na parte aérea das mudas de aceroleira aumentou linearmente em função das doses de nitrogênio, sendo o maior acúmulo de $114,5 \mathrm{mg}$ planta $^{-1}$ alcançado com a dose de $600 \mathrm{mg} \mathrm{dm}^{-3}$, o que correspondeu a um acúmulo 15 vezes maior que na ausência da aplicação do nitrogênio (Figura 5A). Estes resultados foram semelhantes aos encontrados por Neves et al. (2007), trabalhando com mudas de umbuzeiro no qual o acúmulo de $\mathrm{N}$ na parte aérea foi de $123 \mathrm{mg}$ $\mathrm{dm}^{-3}$ e diferiram dos resultados encontrados por Tanure et al. (2017) que estudando mudas de pinhão manso, observou um acúmulo na parte aérea de 423,01 $\mathrm{mg}$ vaso ${ }^{-1}$.

A alta quantidade acumulada de $\mathrm{N}$ e consequentemente a maior necessidade das plantas em relação a este nutriente está diretamente ligada ao rápido desenvolvimento vegetativo em plantas novas (MALAVOLTA, 1980). A alta exigência dessa frutífera por nitrogênio em ramos e folhas é relatada por diversos autores (CIBES; SAMUELS, 1995; FREIRE, 1995; NASCIMENTO, 1995).

Figura 5. Acúmulo de $N(A), C a(B), M g(C)$ e $S(D)$ na matéria seca da parte aérea de mudas de aceroleiras em função da adubação nitrogenada.
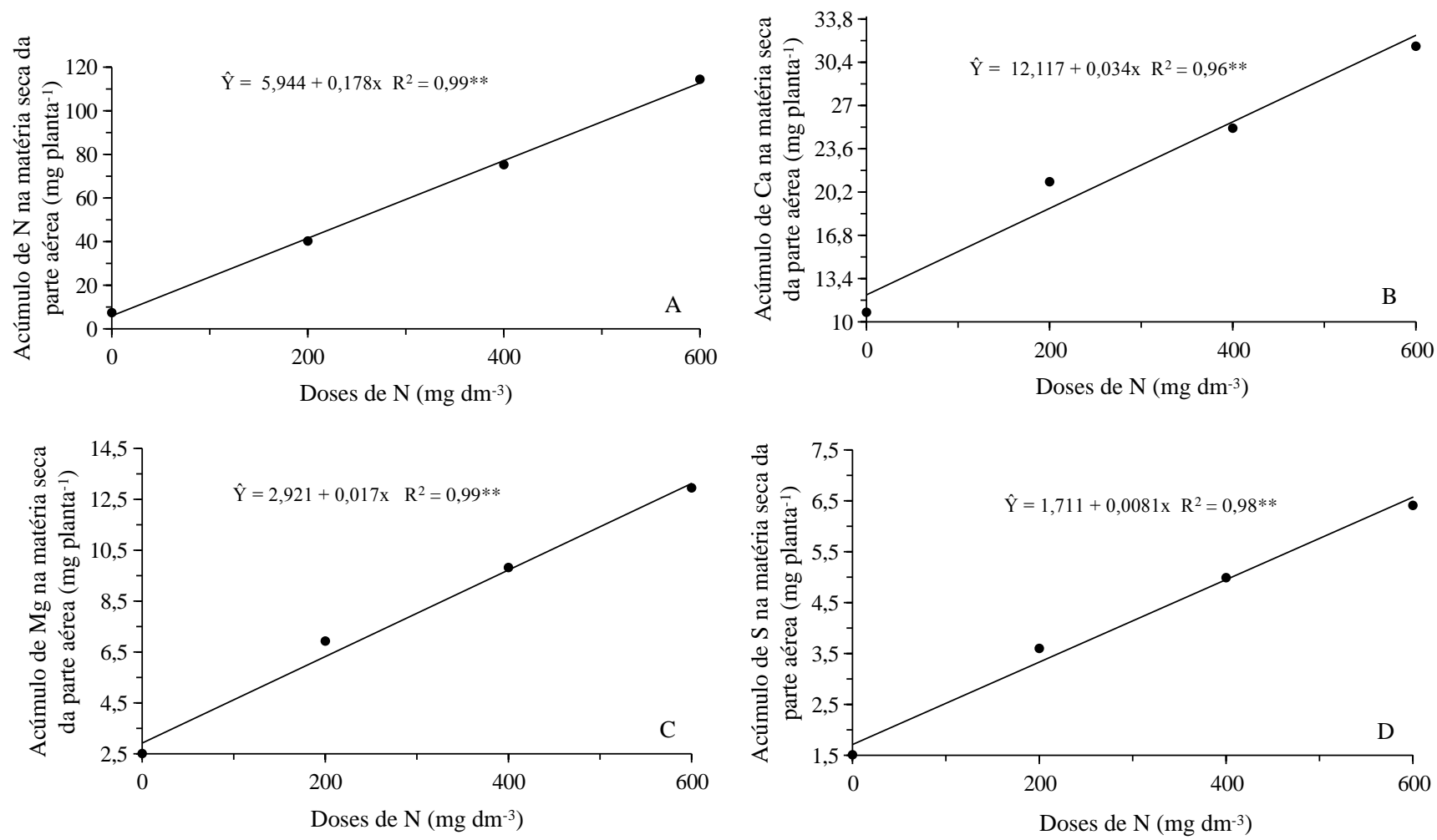

Pode-se inferir também, que a adição de $\mathrm{N}$ favoreceu o acúmulo do Ca (Figura 5B), Mg (Figura $5 \mathrm{C}$ ) e $\mathrm{S}$ (Figura 5D), com acúmulo na parte aérea de 31,$7 ; 12,9$ e $6,41 \mathrm{mg}$ planta $^{-1}$, respectivamente. Resultando em incrementos no acúmulo de 20,9; 10,4 e 4,9 mg planta ${ }^{-1}$ para $\mathrm{Ca}$, $\mathrm{Mg}$ e S com a adição de $600 \mathrm{mg} \mathrm{dm}^{-3}$ de nitrogênio. Corrêa et al. (2002), trabalhando com mudas de aceroleiras submetidas a diferentes doses de fósforo e zinco, encontraram resultados semelhantes ao do presente estudo para o acúmulo de Ca $\left(25,54 \mathrm{mg}\right.$ planta $\left.^{-1}\right), \mathrm{Mg}(19,23 \mathrm{mg}$ planta $\left.{ }^{-1}\right)$ e $S\left(6,45 \mathrm{mg}\right.$ planta $\left.{ }^{-1}\right) .0$ maior acúmulo de $\mathrm{Ca}$ em relação a adubação nitrogenada, possivelmente está relacionada com a formação de pares iônicos entre o $\mathrm{Ca}$ e o nitrato. Maiores teores de nitrato contribuem na dinâmica dos nutrientes catiônicos no solo, pois o ânion $\mathrm{NO}^{3-}$ é considerado íon acompanhante de $\mathrm{Ca}^{2+}, \mathrm{Mg}^{2+}, \mathrm{K}^{+}$ e $\mathrm{Al}^{3+}$ (ROSOLEM; FOLONI; OLIVEIRA, 2003) e, assim, provavelmente, houve melhorias na absorção. Nota-se que em relação ao acúmulo $\mathrm{S}$, o incremento em conjunto de $\mathrm{N}$ (Figura 5A) e enxofre (Figura 5D) tem importância 
vital para a planta, uma vez que Marschner (2005) recomenda adubação equilibrada de nitrogênio e enxofre devido à relação negativa entre esses elementos podendo levar a planta à deficiência de enxofre, o que frequentemente ocorre quando se usa fonte nitrogenada além do recomendado para a cultura e sem a presença do enxofre na composição. Segundo Malavolta et al. (1997), o excesso de nitrato ( $\mathrm{N}-\mathrm{NO}^{3-}$ ) pode promover redução na absorção de sulfato $\left(\mathrm{SO}_{4}{ }^{2-}\right)$ por algumas plantas, pela inibição competitiva.

As quantidades acumuladas de $\mathrm{P}$ e $\mathrm{K}$ apresentaram efeito linear crescente com as doses isoladas de $\mathrm{N}$ e K. O maior acúmulo de $\mathrm{P}$ $\left(7,20 \mathrm{mg}\right.$ planta $\left.^{-1}\right)$ e $\mathrm{K}\left(4,48 \mathrm{mg}\right.$ planta $\left.^{-1}\right)$ foi observado na dose de $600 \mathrm{mg} \mathrm{dm}^{-3}$ de N (Figura $6 \mathrm{~A}$ e 6B). Para as doses isoladas de $\mathrm{K}$ utilizadas verificou-se maior acúmulo de $\mathrm{P} \quad(5,04 \mathrm{mg}$ planta $\left.^{-1}\right)$ e K (3,15 mg planta $\left.{ }^{-1}\right)$ em $300 \mathrm{mg} \mathrm{dm}^{-3}$ de $\mathrm{K}$ (Figura 7A e 7B). $O$ baixo acúmulo verificado para o $\mathrm{P}$ em relação aos demais macronutrientes, pode ter ocorrido, devido à adubação feita no transplantio das mudas onde foi utilizada uma quantidade satisfatória de $\mathrm{P}$, conforme Corrêa et al., (2002). Segundo Faquin (2005), de maneira geral, as plantas apresentam menor exigência por $\mathrm{P}$ em relação aos nutrientes $\mathrm{N}, \mathrm{K}, \mathrm{Ca}$ e $\mathrm{Mg}$.

Figura 6. Acúmulo de $P(A)$ e $K(B)$ na matéria seca da parte aérea de mudas de aceroleiras em função da adubação nitrogenada.

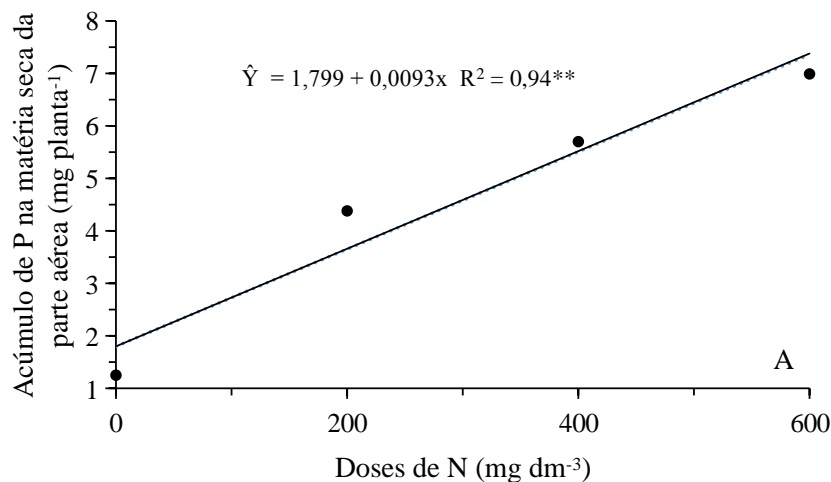

Para $\mathrm{o} \mathrm{K}$ a disponibilidade nutricional presente no substrato antes da adubação, possivelmente, encontrava-se além dos críticos exigidos pela cultura para seu crescimento, em consequência, do baixo acúmulo verificado nas mudas. Além disso, a absorção de nutrientes em uma superfície de alta densidade de cargas, preferencialmente, há atração por cátions de maior valência, como os bi e trivalentes, a exemplo do $\mathrm{Ca}^{2+}$ e $\mathrm{Mg}^{2+}$ (SOUZA; FERNANDES, 2006).

De forma geral com o aumento das doses de $\mathrm{N}$ há um incremento no acúmulo dos

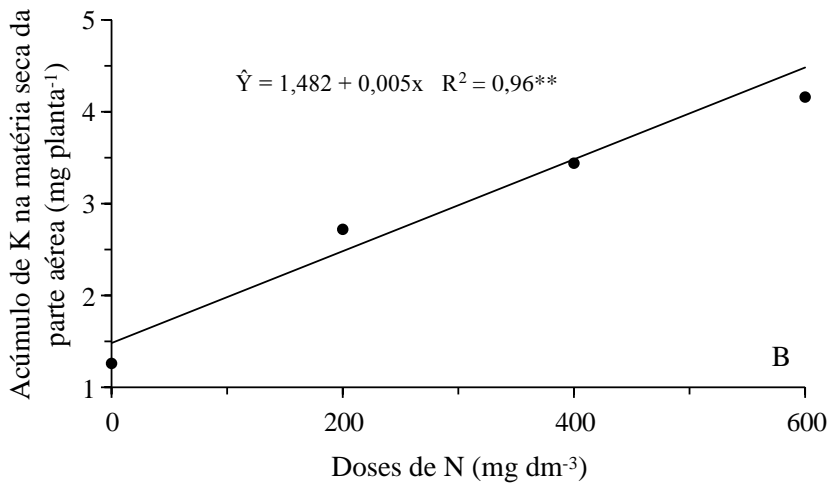

macronutrientes que pode estar relacionado com o papel direto que o nitrogênio desempenha na fotossíntese, visto que Dechen e Natchtigall (2007) observaram que deficiência de nitrogênio reduz a síntese de clorofila; nessa condição, a planta não pode usar a luz solar como fonte de energia para a fotossíntese, resultando em uma perda de capacidade para executar funções essenciais, como a absorção de nutrientes. 
Figura 7. Acúmulo de $P(A)$ e $K$ (B) na matéria seca da parte aérea de mudas de aceroleiras em função da adubação potássica.

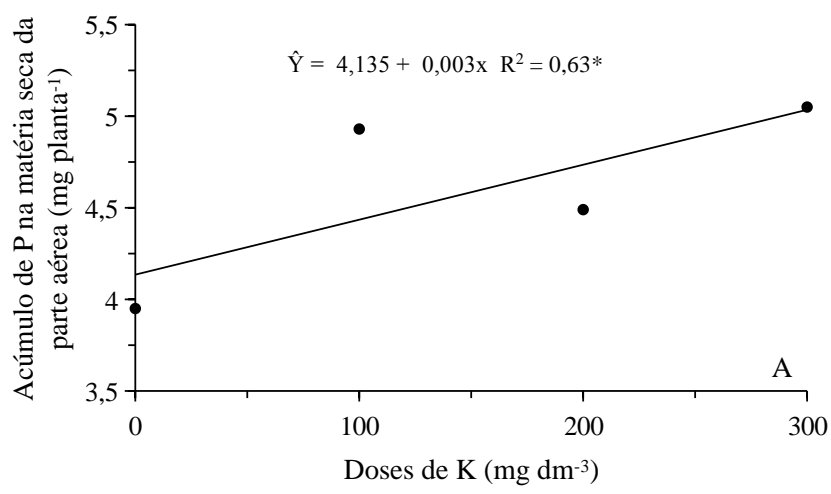

O acúmulo do micronutriente $\mathrm{Zn}$ na parte aérea ajustou de forma linear a aplicação isolada de nitrogênio e potássio, verificando um acúmulo $90,64 \mathrm{\mu g}$ planta ${ }^{-1}$ na dose de $600 \mathrm{mg} \mathrm{dm}^{-3}$ de nitrogênio e 59,48 $\mu \mathrm{g}$ planta $^{-1}$ na dose de $300 \mathrm{mg}$ $\mathrm{dm}^{-3}$ de potássio (Figura $8 \mathrm{~A}$ e $8 \mathrm{~B}$ ). Comportamento semelhante foi constado por Dias et al. (2012) com mudas de goiabeira em

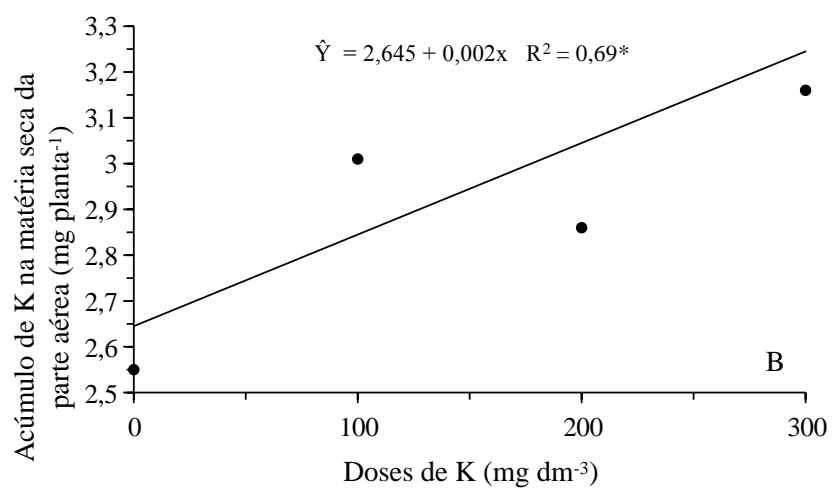

relação a adubação potássica, onde houve um incremento do acúmulo de $\mathrm{Zn}$ em relação ao aumento da adubação potássica, entretanto, os resultados dos mesmos autores diferiram do presente estudo em relação a adubação nitrogenada, no qual a resposta foi quadrática.

Figura 8. Acúmulo de Zn (A) e (B) na matéria seca da parte aérea de mudas de aceroleiras em função da adubação nitrogenada e potássica isoladamente.

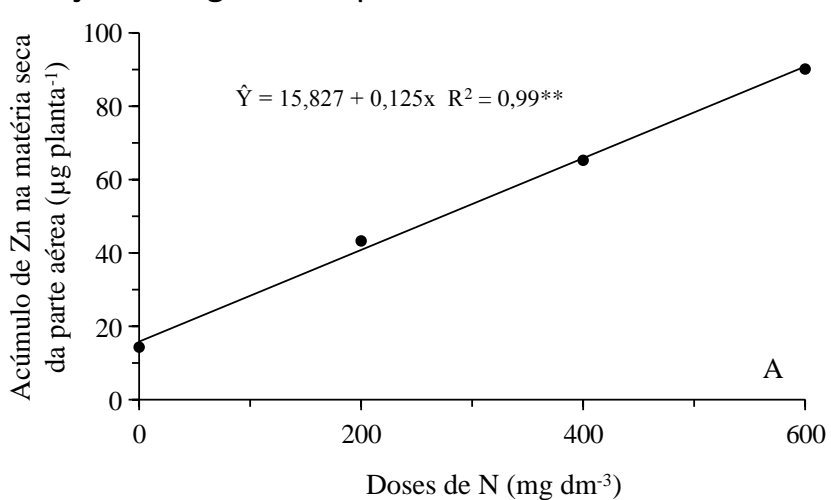

Verificou-se um acúmulo máximo de 18,39 e $678,93 \mathrm{\mu g}$ planta $^{-1}$ na dose de $600 \mathrm{mg} \mathrm{dm}^{-3}$ de N para Fe e $\mathrm{Mn}$, respectivamente (Figura 9A e 9B). $\mathrm{Em}$ relação o $\mathrm{Fe}$, este apresentou um acúmulo inferior ao encontrado por Corrêa et al. (2002) em folhas de aceroleira $\left(132,7 \mu \mathrm{g}\right.$ planta $\left.{ }^{-1}\right)$, contudo, para o $\mathrm{Mn}$ o acúmulo deste estudo foi superior, evidenciando que $o$ nitrogênio aumentou a disponibilidade do Mn. Segundo Malavolta e Neptune (1983), a utilização de "adubos fisiologicamente ácidos", contendo nitrogênio na forma $\mathrm{N}-\mathrm{NH}_{2}$ ou $\mathrm{N}-\mathrm{NH}_{4}$, reduz o $\mathrm{pH}$

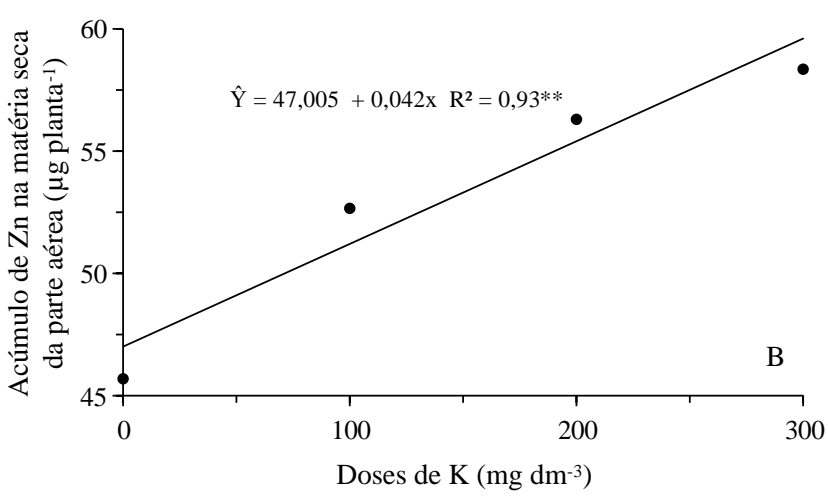

do solo, aumentando a disponibilidade e, consequentemente, a absorção de micronutrientes, podendo atingir níveis tóxicos. Em contrapartida, o baixo acúmulo de Fe pode ser explicado pelo fato que altas concentrações de $\mathrm{Mn}$, uma vez que esse micronutriente inibe a absorção de $\mathrm{Fe}$ e alta concentração de $\mathrm{Mg}$, inibe a absorção de $\mathrm{Mn}$, assim de forma geral plantas com baixo acúmulo de $\mathrm{Mn}$ apresentam altos teores de Fe e Mg (MALAVOLTA et al., 1997). 
Figura 9. Acúmulo de Fe (A) e Mn (B) na matéria seca da parte aérea de mudas de aceroleiras em função da adubação nitrogenada.

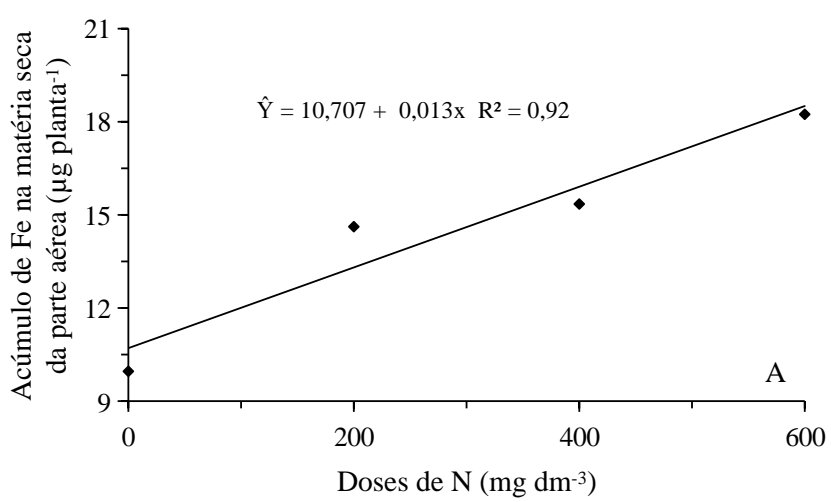

O modelo quadrático foi o que melhor se ajustou ao acúmulo de $B$ em mudas de acerola, sendo que o máximo acúmulo ocorreu na dose de $507 \mathrm{mg} \mathrm{dm}^{-3}$ de $\mathrm{N}$, sendo acumulado $110,18 \mu \mathrm{g}$ planta ${ }^{-1}$, resultando em um incremento de 4 vezes em relação a testemunha (Figura 10). Resultado semelhante para o B foi observado por (NATALE et al., 2006; NEVES et al., 2007; DIAS et al., 2012) em função da adubação nitrogenada em goiaba.

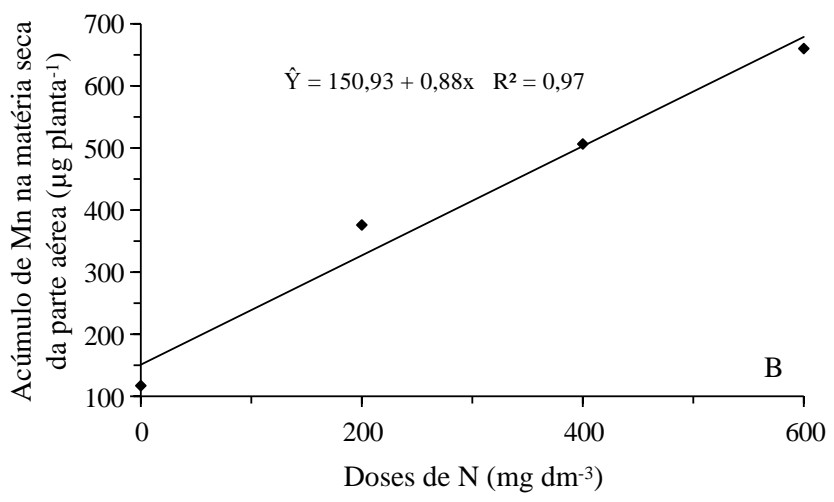

O boro é um nutriente em que sua principal função está relacionada ao desenvolvimento da parede celular, interligando moléculas que fornecerão reforço físico à mesma, além de servir em outros processos celulares, como o metabolismo do ácido ribonucleico (RNA) (PILBEAM; KIRKBY 1983; ALI; JARVIS, 1988) e funções da membrana (PARR; LOUGHMAN, 1983).

Figura 10. Acúmulo de B na matéria seca da parte aérea de mudas de aceroleiras em função da adubação nitrogenada.

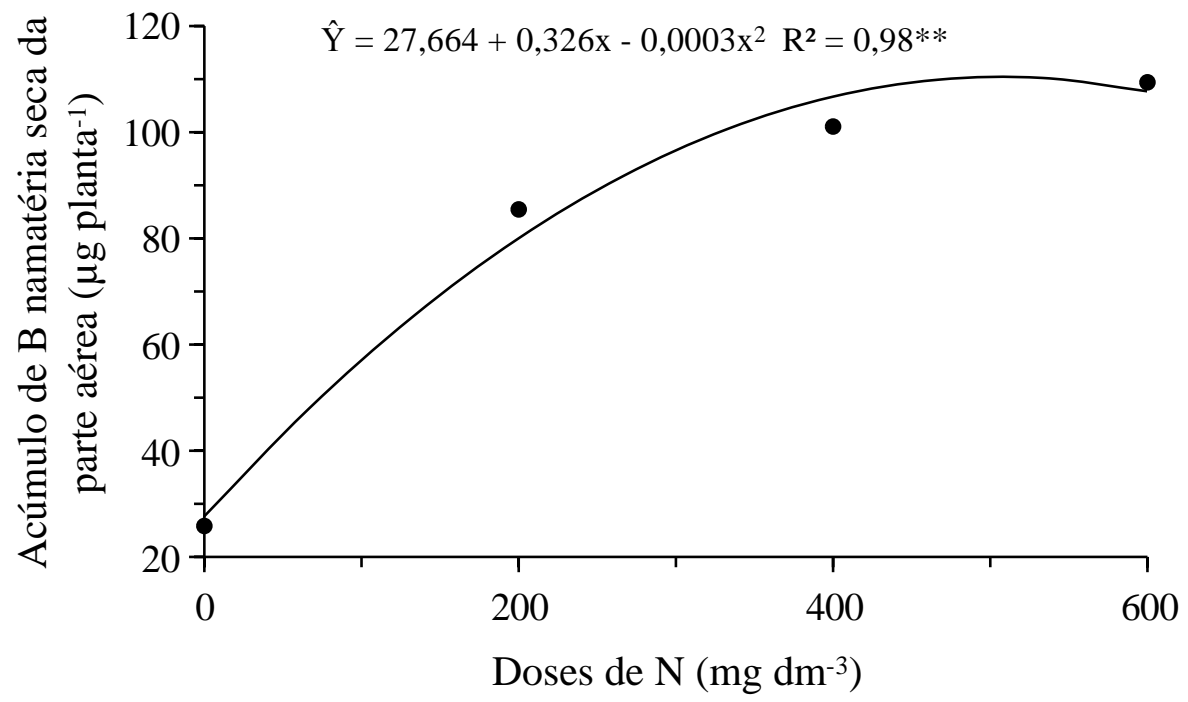

O acúmulo de nutrientes nas mudas de aceroleiras apresentou a seguinte ordem decrescente para os macronutrientes $\mathrm{N}>\mathrm{Ca}>\mathrm{Mg}>\mathrm{P}>\mathrm{S}>\mathrm{K}$ e para os micronutrientes $M n>B>Z n>F e$. Variações na ordem de absorção e acúmulo de nutrientes em mudas de frutíferas são comumente relatadas na literatura, quando se empregam materiais genéticos e meios de cultivo distintos. A quantidade de nutrientes absorvida pelas plantas é função das condições edafoclimáticas e das características genéticas da planta.

\section{CONCLUSÃO}

O crescimento e acúmulo dos nutrientes avaliados foram influenciados pela aplicação de nitrogênio e potássio ao substrato em mudas de aceroleiras. 
As doses de $600 \mathrm{mg} \mathrm{dm}^{-3}$ de $\mathrm{N}$ e $300 \mathrm{mg} \mathrm{dm}^{-3}$ de $\mathrm{K}$ foram as que melhor incrementaram o crescimento das plantas de acordo com o Índice de Qualidade de Dickson e o comprimento da parte aérea.

As doses de $600 \mathrm{mg} \mathrm{dm}^{-3}$ e $300 \mathrm{mg} \mathrm{dm}^{-3}$ de $\mathrm{N}$ e $\mathrm{K}$, respectivamente, provocaram um maior acúmulo dos nutrientes seguindo a ordem decrescente de acúmulo nas mudas $\mathrm{N}>\mathrm{Ca}>\mathrm{Mg}>\mathrm{P}>\mathrm{S}>\mathrm{K}>\mathrm{Mn}>\mathrm{B}>\mathrm{Zn}>\mathrm{Fe}$.

Estudos relacionados com exigência nutricional da aceroleira ainda são escassos e possivelmente a aplicação de doses maiores de $\mathrm{N}$ e $\mathrm{K}$ poderiam conferir maiores quantidades acumuladas nos tecidos vegetais e contribuir na calibração das doses de nutrientes no crescimento das mudas.

\section{REFERÊNCIAS}

ABANTO-RODRÍGUEZ, C.; CHAGAS, E. A.; ALBUQUERQUE, T. C. S. de.; SOUZA, A. G.; ARAÚJO, W. F.; CHAGAS, P. C.; ANDRADE, J. K. C.; SOUZA, O. M. Crescimento inicial de plantas de camu-camu sob fertirrigação com potássio em condições de terra firme. Folia Amazónica, v.23, n.1, p.7-16, 2014. https://doi.org/10.24841/fa.v23i1.3

ALI, A. H. N.; JARVIS, B. C. Effects of auxin and boron on nucleic-acid metabolism and cell-division during adventitious root regeneration. New Phytologist, v.108, p. 383-391, 1988.

https://doi.org/10.1111/j.1469-8137.1988.tb0417 8.x

ALMEIDA, M. O.; CRUZ, M. D.; de CASTRO, G. D.;FAGUNDES, M. C. P. Crescimento e absorção de nutrientes por mudas de maracujazeiro-amarelo em substratos orgânico e comercial e adubação nitrogenada. Revista Brasileira de Ciências Agrárias, v.9, n.2, p.180-185, 2014. https://DOI:10.5039/agraria.v9i2a3593

ARMENGAUD, P.; SULPICE, R.; MILLER, A. J.; STITT, M.; AMTMANN, A.; GIBON, Y. Multilevel analysis of primary metabolism provides new insights into the role of potassium nutrition for glycolysis and nitrogen assimilation in Arabidopsis roots. Plant Physiology, v.150, p.772-785, 2009. https://doi.org/10.1104/pp.108.133629

ASSIS, S. A.; LIMA, D. C.; OLIVEIRA, O. M. M. D. Activity of pectinmethylesterase, pectin content and vitamin $C$ in acerola fruit at various stages of fruit development. Food Chemistry, v. 74, n. 2, p.133-137, 2001. https://doi.org/10.1016/S0308-8146(01)00104-2

AZEVEDO, M. I. R. Qualidade de mudas de cedro-rosa (Cedrela fissilis Vell.) e de ipê-amarelo (Tabebuia serratifolia (Vahl) Nich.) produzidas em diferentes substratos e tubetes. 2003. 90f. Dissertação (Mestrado em Ciência Florestal) - Universidade Federal de Viçosa, Viçosa, 2003.

CALDEIRA, M. V. W.; DELARMELINA, W. M.; LÜBE, S. G.; GOMES, D. R.; GONÇALVES, E. O.; ALVES, A. F. Biossólido na composição de substrato para a produção de mudas de Tectona grandis. Revista Floresta, v.42, n.1, p.77-84, 2012. http://dx.doi.org/10.5380/rf.v4i1.26302

CIBES, H.; SAMUELS, G. Mineral deficiency symptoms displayed by acerola trees grown in the greenhouse under controlled conditions. Rio Piedras: University of Puerto Rico, 1995. (Technical Paper, 15)

CORRÊA, F. L. O.; SOUZA, C. A. S.; CARVALHO , J. G.; MENDONÇA, V. Fósforo e zinco no desenvolvimento de mudas de aceroleira. Revista Brasileira de Fruticultura, v.24, n.3, p.793-796, 2002.

https://doi.org/10.1590/S0100-29452002000300 060

DANIEL, O.; VITORINO, A. C. T.; ALOVISI, A. A. Aplicações de Fósforo em Mudas de Acacia manginum Willd. Revista Árvore, v.21, n.2, p.163-168, 1997.

DECHEN, A. R.; NACHTIGALL, G. R. Elementos requeridos à nutrição de plantas. In: NOVAIS, R. F.; ALVAREZ-V, V. H.; BARROS, N. F.; FONTES, R. L. F.; CANTARUTTI, R. B.; NEVES, J. C. L. (Eds.). Fertilidade do solo. Viçosa: SBCS, 2007. p. 91-132.

DIAS, M. J. T.; SOUZA, H. A.; NATALE, W.; MODESTO, V. C.; ROZANE, D. E. Adubação com nitrogênio e potássio em mudas de goiabeira em viveiro comercial. Semina: Ciências Agrárias, v.33, supl. $\quad 1, \quad$ p.2837-2848, 2012. https://doi.org/10.5433/1679-0359.2012v33Supl1 p2837 
DICKSON, A.; LEAF, A. L.; HOSNER, J. F. Quality appraisal of white spruce and white pine seedling stock in nurseries. Forestry Chronicle, v.36, n. 1, p.10-13, 1960. https://doi.org/10.5558/tfc36010-1

DURIEUX, R. P.; KAMPRATH, E. .J; JACKSON, W. A; MOLL, R. H. Root distribution of corn the effect of nitrogen fertilization. Agronomy Journal, v. 86, p.958-962, 1994. http://doi:10.2134/agronj1994.000219620086000 $60006 x$

FAQUIN, V. Nutrição mineral de plantas. Lavras: ESAL FAEPE, 1994.

FAQUIN, V. Nutrição Mineral de Plantas. Lavras: UFLA/FAEPE, 2005.

FERREIRA, D. F. Sisvar: a computer statistical analysis system. Ciência e. agrotecnologia, v.35, n.6, p.1039-1042, 2011. http://dx.doi.org/10.1590/S1413-705420110006 00001

FREIRE, J. L. de O. Acerola (Malpighia sp) concentrações de NPK em plantas e caracterização físico-química de frutos em pomares de diferentes regiões da Paraíba. 1995. Dissertação (Mestrado em Ciências Agrárias) - Universidade Federal da Paraiba, Areia, 1995.

GOMES, J. M.; COUTO, L.; LEITE, H. G.; XAVIER, A.; GARCIA, S. L. R. Parâmetros morfológicos na avaliação da qualidade de mudas de Eucalyptus grandis. Revista Árvore, Viçosa, v.26, n.6, p.655-664, 2002. https://doi.org/10.1590/\$0100-67622002000600 002

HARPER, J. E. Nitrogen metabolism. In: BOOTE, K. J.; BENNETT, J. M.; SINCLAIR, T. R.; PAULSEN, G. $M$., eds. Physiology and determination of crop yield. Madison: ASA/CSSA/SSSA, 1994. p.285-302.

HERMANN, R. K. Importance of top-root ratios for survival of Douglas-fir seedlings. Tree Planters Notes, v. 64, p. 7-11, 1964.

KIRKBY, E. A.; RÖMHELD, V. Micronutrientes na fisiologia de plantas: funções, absorção e mobilidade. Informações agronômicas, n.118, 24p, 2007.
LEAL, R. M.; NATALE, W.; MELLO PRADO, R.; ZACCARO, R. P. Adubação nitrogenada na implantação e na formação de pomares de caramboleira. Pesquisa agropecuária brasileira, v.42, n.8, p.1111-1119, 2007. https://doi.org/10.1590/S0100-204X2007000800 007

LEBAUDY, A.; VÉRY, A. A.; SENTENAC, H. $\mathrm{K}^{+}$ channel activity in plants: genes, regulations and functions. FEBS letters, v.581, n.12, p.2357-2366, 2007.

https://doi.org/10.1016/j.febslet.2007.03.058

MALAVOLTA, E. Elementos de nutrição mineral de plantas. São Paulo: Ceres, 1980.

MALAVOLTA, E.; NEPTUNE, A. M. L. Características e eficiência dos adubos nitrogenados. São Paulo: SN Centro de Pesquisa e Promoção de Sulfato de Amônio, 1983. (SN Boletim técnico, 2).

MALAVOLTA, E.; VITTI, G. C.; OLIVEIRA, S. A. Avaliação do estado nutricional das plantas: princípios e aplicações. 2. ed. Piracicaba: Potafós, 1997.

MALAVOLTA, E. Manual de nutrição mineral de plantas. São Paulo: Agronômica Ceres, 2006.

MARSCHNER, $H$. Mineral nutrition of higher plants. 2 ed. London: Academic Press, 1995.

MENDONÇA, V.; RAMOS, J. D.; ABREU, N. A. A.; TEIXEIRA, G. A.; SOUZA, H. A.; GURGEL, R. L. S.; ORBES, $M, Y$. Adubação nitrogenada em cobertura e substratos na produção de mudas de mamoeiro 'formosa'. Ciência e Agrotecnologia, v.33, n.3, p. 68-675, 2009. https://doi.org/10.1590/S1413-70542009000300 002

MENDONÇA, V.; TOSTA, M. S.; MENDONÇA, L. F. M.; BISCARO, G. A., FREITAS, P. S. C.; PAREIRA, E. C.; LEITE, G. A. Doses crescentes de nitrogênio sobre o crescimento inicial de porta-enxertos de cajueiro gigante. Revista Agrarian, v.3, n.8, p.95-103, 2010.

MENGEL, K., HELAL, M. Der Einfluss einer variierten $\mathrm{N}$ - und K-Ernährung auf den Gehalt an löslichen Amino-verbindungen in der 
oberirdischen Pflanzenmasse von Hafer. Z Pflanzenernaehr Bodenk, v.120, p.12-20, 1968. https://doi.org/10.1002/jpln.19681200103

MIYAKE, R. T. M.; CRESTE, J. E.; NARITA, N.; GUERRA, W. E. X. Substrato e adubação nitrogenada na produção de mudas de maracujazeiro amarelo em condições protegidas. Colloquium Agrariae, v.13, n.1, p.57-65, 2017. https://doi.org/10.5747/ca.2017.v13.n1.a149

NASCIMENTO, L. C. Teores de nitrogênio, fósforo e potássio em plantas de acerola (Malpighia sp) cultivadas nas regiões do Cariri e Brejo Paraibano. 1995. Monografia - Universidade Federal da Paraiba, Areia, 1995.

NATALE, W.; PRADO, R. M.; ALMEIDA, E.V de.; BARBOSA, J. C. Adubação nitrogenada e potássica no estado nutricional de mudas de maracujazeiro-amarelo. Acta Scientiarum Agronomy, v.28, n.2, p.187-192, 2006. https://doi.org/10.4025/actasciagron.v28i2.1036

NEVES, O. S. C.; CARVALHO, J. D.; FERREIRA, E. V. D. O.; PEREIRA, N. V. Crescimento, nutricao mineral e nível crítico foliar de $\mathrm{K}$ em mudas de umbuzeiro, em função da adubação potássica. Ciência e Agrotecnologia, v.31, n.3, p.636-642, 2007. https://doi.org/10.1590/S1413-70542007000300 006

OOSTERHUIS, D. M.; LOKA, D. A.; KAWAKAMI, E. M.; PETTIGREW, W. T. The physiology of potassium in crop production. Advances in Agronomy, v.126, p.203-233, 2014. https://doi.org/10.1016/B978-0-12-800132-5.00 003-1

PARR, A. J.; LOUGHMAN, B. C. Boron and membrane function in plants. In: Robb, D.A.; W.S. Pierpoint (Eds.). Metal and Micronutrients: Uptake and Utilization by Plants. London: Academic Press, $1983 . \quad$ p.87-107. https://doi.org/10.1016/B978-0-12-589580-4.500 $12-2$

PAULA, Y. C. M.; MENDONÇA, V.; DE GÓES, G. B.; LIMA, A. S.; de MEDEIROS, L. F.; de VASCONSELOS BATISTA, T. M. Doses de sulfato de potássio na produção de porta-enxerto de tamarindeiro (Tamarindus indica L.). Revista Agrarian, v.2, n.5, p.71-79, 2009. https://doi.org/10.30612/agrarian.v2i5.805

PILBEAM, D. J.; KIRKBY, E.A. The physiological role of boron in plants. Journal of plant nutrition, v.6, n.7, p.563-582, 1983. https://doi.org/10.1080/01904168309363126

ROSOLEM, C. A.; FOLONI, J. S. S.; OLIVEIRA R. H. Dinâmica do nitrogênio no solo em razão da calagem e adubação nitrogenada, com palha na superfície. Pesquisa Agropecuária Brasileira, v.38, n.2, p.301-309, 2003. https://doi.org/10.1590/S0100-204X2003000200 018

SILVA, C. P.; GARCIA, K. G. V.; SILVA TOSTA, M.; CUNHA, C. S. M.; NASCIMENTO, C. D. V. Adubação nitrogenada no crescimento inicial de mudas de jaqueira. Enciclopédia biosfera, v.10, n.18, p.174-180, 2014.

SOUZA, S. R.; FERNANDES, M. S. Nitrogen-acquisition by plants in a sustainable environment. In: SINGH, R.P.; JAIWAL, P.K. (Ed.). Biotechnological Approaches to Improve Nitrogen Use Efficiency in Plants. Houston, Texas: Studium Press, 2006. p.41-62.

TANURE, L. P. P.; SILVA, E. B.; PEREIRA, G. A. M.; NARDIS, B. O.; FERREIRA, E. A. Requerimento, acúmulo e distribuição de macronutrientes em mudas de pinhão-manso. Cultura Agronômica, v.26, n.3, p.443-455, 2017. 